\title{
Zu den Briefen des Michael Glykas.
}

In B. Z. XVII 166-172 hat Ed. Kurtz die von Eustratiades veranstaltete Ausgabe von Briefen des Michael Glykas (Athen 1906) eingehend besprochen. Zu zwei Punkten dieser Besprechung möchte ich mir einige Worte erlauben.

I. Zur Fußnote auf Seite 169, betr. Dräsekes Datierang der Synode gegen Soterichos Panteugenos. Die Einfügung der fraglichen Synode in den zeitlichen Zusammenhang mit Manuels Zug nach Kilikien ist doch nicht ohne irgendwelche Grundlage, sondern entspricht genau dem Berichte des Kinnamos (IV. 16). Als Jahr dieses Feldzuges ist auch nach Wilhelm von Tyrus 1158 anzunehmen. Doch fällt nach diesem Manuels Ankunft in $K$. in den Dezember, nicht September (lib. XVIII. c. 23).

Die Bezeugung des Datums der Synoden in den von A.Mai herausgegebenen Akten derselben ist nicht so unbedingt zuverlässig, daB sie allein gegen Kinnamos zu entscheiden hätte. Im Bericht über den zweiten Verhandlungstag (13. Mai) ist die Indiktionsziffer sogar gröblich falsch (s. bei Mai S. 82). Es ist aber auf anderem Wege allerdings urkundlich zu beweisen, daB die Synode vor 1158, also 1157 stattgefunden haben muB. Sie hat nämlich nach den Akten zweifellos nosh unter dem Patriarchat des Konstantinos Chliarenos getagt. Für Ende 1157 ist aber schon dessen Nachfolger Lukas Chrysoberges als Patriarch nachweisbar, s. Balsamon zu can. XVI. conc. Carthag. (Migne Bd. 138 S. 88 und Bd. 119 S. 773). Daraus folgt, daB Kinnamos sich tatsächlich geirrt haben muB. ' Es ist auch wirklich $\mathrm{zu}$ beweisen -. wenn auch nicht in einer kurzen Bemerkung, - daB seine Darstellung gerade in dem Zusammenhang, auf den es ankommt, chronologisch nicht einwandsfrei ist. - Beiläufig sei darauf aufmerksam gemacht, daB nach Wilhelm von Tyrus der Zng Manuels nach Kleinasien mit ganz besonderer Eile ausgeführt wurde, um die Gegner zu überraschen, was auch gelang. Wenn aber Manuel doch erst gegen Ende des Jahres oder, um Vasiljevskij und dem Fortsetzer des Matthaios von Edessa. zu folgen - immerhin erst gegen Ausgang des Sommers in K. ankam, 
während er schon im Mai im Begriff gewesen wäre, ins Feld zu ziehen, so könnte nicht gerade von besonderer Beschleunigung gesprochen werden. Auch dies erregt Bedenken gegen den Bericht des Kinnamos.

II. Zu dem Brief $\pi \delta^{\prime}$ des Glykas über das Abendmahl. Es hat von Anfang an meine Verwunderung erweckt, daB selbst Krumbacher den Inhalt dieses Briefes als nicht bekannt vorausgesetzt und daraufhin sogar gegen die Gleichsetzung des Glykas mit Sikidites geltend gemacht hat, daB in diesem Briefe jedenfalls in rechtgläubigem Sinne werde gelehrt worden sein (Monographie über Glykas, Sitzungsber. der Kgl. bayer. Akademie 1894 S. 546 [statt 446 zu lesen]). Tatsächlich hat doch schon Leo Allatius den Brief bekannt gemacht, s. Adversus Creyghton. exercit. XXII S. 545, vgl. dazu auch S. 433 und 541. Allatius zeigt sich dort auch wohl darüber unterrichtet, daB Glykas' Briefe irrig dem Zonaras zugewiesen wurden.

Kohlow.

H. Pachali. 